\title{
EVALUASI FAKTOR-FAKTOR PENTING PENYEBAB PENAMBAHAN BIAYA PROYEK JALAN APBD KABUPATEN SRAGEN TAHUN 2017 DAN 2018
}

\author{
Muhammad Nur Sahid ${ }^{1}$, Anto Budi L², Abdul Rochman³ ${ }^{3}$, Devi Cahyaningtyas ${ }^{4}$ \\ 1,2,3 Dosen Jurusan Teknik Sipil, Fakultas Teknik, Universitas Muhammadiyah Surakarta \\ ${ }^{4}$ Mahasiswa Jurusan Teknik Sipil, Fakultas Teknik, Universitas Muhammadiyah Surakarta \\ ${ }^{1}$ mns260@ums.ac.id; ${ }^{2}$ anto.budi@ums.ac.id; ${ }^{3}$ ar126@ums.ac.id; \\ 4d100150193@student.ums.ac.id
}

\begin{abstract}
The development of a country can be known by the expansion of its transportation facilities. Looking at the importance of roads for a region, there are many improvements and additions to these facilities and infrastructure. In the process of repairing the roads, some risks could be possibly causing failures such as time delay and cost overrun. The purpose of this study is to determine the important and the dominant factors that lead to the overrun cost to the road projects in Sragen Regency in 2017 and 2018. The data were obtained by distributing the questionnaires to the contractors who had handled the road projects in Sragen Regency. The results of the questionnaires survey collected 98 questionnaires of 55 contractors. The data analysis is using the program SPSS (Statistical Package for Social Science) Ver 25.0. The results of this study are the factors that cause overrun cost to the road projects in Sragen Regency in 2017 and 2018, are the implementation and the relationship of work and equipment, and the dominant factors that cause overrun cost to road projects in Sragen Regency in 2017 and 2018 is the implementation and the relationship of work.
\end{abstract}

\section{Keywords: additional project costs, cost overrun, road projects}

Abstraksi. Kemajuan sebuah bangsa dapat diukur dengan melihat kemajuan dan perkembangan transportasinya. Menyadari akan pentingnya jalan bagi suatu daerah, maka sekarang ini banyak dilakukan perbaikan dan penambahan sarana dan prasarana tersebut. Dalam pelaksanaan perbaikan jalan terdapat risiko yang tidak menutup kemungkinan akan menyebabkan terjadinya kegagalan proyek baik berupa keterlambatan waktu maupun penambahan biaya (cost overrun). Penelitian ini dilakukan dengan tujuan untuk mengetahui faktor penting dan faktor dominan yang menjadi penyebab penambahan biaya proyek jalan APBD Kabupaten Sragen tahun 2017 dan 2018. Data yang digunakan dalam penelitian ini diperoleh melalui penyebaran kuesioner kepada kontraktor yang menangani proyek jalan APBD di Kabupaten Sragen pada tahun 2017 dan 2018. Setelah dilakukan penyebaran kuesioner, diperoleh 98 kuesioner dengan 55 kontraktor. Analisis pengolahan data menggunakan bantuan program SPSS (Statistical Package for Social Science) Ver 25.0. Hasil dari penelitian ini diperoleh faktor-faktor yang menjadi penyebab penambahan biaya proyek jalan APBD Kabupaten Sragen tahun 2017 dan 2018 adalah pelaksanaan \& hubungan kerja dan peralatan, serta faktor dominan yang menjadi penyebab penambahan biaya proyek jalan APBD Kabupaten Sragen tahun 2017 dan 2018 adalah pelaksanaan \& hubungan kerja.

Kata kunci: penambahan biaya proyek, cost overrun, proyek jalan. 


\section{PENDAHULUAN}

Dengan adanya perkembangan pada sarana transportasi di Indonesia maka untuk mengimbanginya perlu dikembangkan pula prasarana transportasi yaitu jalan raya dan jembatan yang sekiranya mampu mendukung mobilisasi perpindahan manusia dan barang, serta mampu memberikan pelayanan terhadap bertambahnya sarana transportasi. Jalan adalah salah satu prasarana transportasi yang dapat mendorong laju pertumbuhan dan perkembangan suatu daerah dalam sektor ekonomi. Suatu daerah yang tidak didukung dengan memiliki jalan yang baik akan cenderung memiliki pertumbuhan ekonomi yang lambat atau rendah.

Dalam sebuah proyek konstruksi pasti terdapat risiko-risiko proyek yang berpotensi terhadap kegagalan pekerjaan yang berupa penundaan pekerjaan dan penambahan biaya. Risiko proyek adalah kemungkinan sebuah peristiwa atau hasil yang tidak dikehendaki terjadi. Terdapat hubungan besarnya risiko dengan besarnya harga penawaran oleh kontraktor, yaitu semakin besar risiko yang terdapat dalam suatu proyek maka semakin besar pula harga yang harus ditawarkan oleh kontraktor dalam kontrak konstruksi. Oleh sebab itu, penting bagi kontraktor untuk mengetaui lebih dalam lagi mengenai risiko-risiko yang terjadi dalam sebuah proyek agar tidak terjadi kegagalan dalam pelaksanaan proyek konstruksi.

Penelitian ini bertujuan untuk mengetahui faktor-faktor penting dan dominan yang menjadi penyebab penambahan biaya proyek jalan APBD Kabupaten Sragen pada tahun 2017 dan 2018.
Manajemen konstruksi adalah upaya yang dilakukan untuk mengaplikasikan sumber daya proyek konstruksi agar lebih efektif dan efisien dalam mencapai tujuan sebuah proyek konstruksi. (Dimyati dan Nurjaman, 2014: 71). Sumber daya dalam proyek konstruksi adalah man power, materials, machines, money, and method. Dengan adanya manajemen yang baik akan membuat pelaksanaan proyek konstruksi berjalan dengan lancar dan sesuai dengan tujuan. Manajemen konstruksi berfungsi sebagai berikut.

a) Menjaga kesesuaian antara perencanaan yang dilakukan dengan pelaksanaan sebuah proyek konstruksi.

b) Meminimalisir terjadinya perubahan kondisi lapangan yang tidak pasti

c) Memantau kemajuan pelaksanaan pekerjaan yang telah tercapai

d) Mengevaluasi tindakan pengambilan keputusan jika terjadi masalah saat di lapangan.

Biaya proyek adalah biaya yang harus dikeluarkan untuk melaksanakan sebuah proyek konstruksi. Biaya proyek dikelompokan menjadi dua komponen, yaitu biaya langsung dan biaya tidak langsung. (Dimyati dan Nurjaman, 2014: 361).

a) Biaya Langsung adalah biaya yang harus dikeluarkan untuk mendapatkan sumber daya yang akan digunakan untuk pelaksanaan proyek. Unsurunsur yang termasuk dalam biaya langsung adalah biaya material, biaya upah, biaya peralatan, dan biaya subkontraktor.

b) Biaya Tidak Langsung adalah biaya yang berhubungan dengan pengeluaran umum diluar biaya konstruksi. 
Estimasi biaya proyek adalah kegiatan pembuatan anggaran biaya proyek untuk menyelesaikan sebuah proyek yang dapat memberikan gambaran tentang jenis pekerjaan dan harga untuk setiap item pekerjaan, serta upah pekerjanya. Estimasi biaya proyek dilakukan untuk memprediksi total biaya proyek yang harus dikeluarkan untuk merealisasikan sebuah bangunan. (Manullang, 2015: 10).

Biaya adalah suatu aspek yang harus dikendalikan seminimum mungkin (Natan, 1986). Pengendalian biaya dilakukan untuk menekan biaya serendah mungkin sehingga tidak terjadi penambahan biaya. Semakin baik tingkat pengendalian biaya pada suatu proyek maka keuntungan proyek akan semakin besar dalam merealisasikan sebuah bangunan.

Penambahan biaya proyek (cost overrun) adalah biaya pada suatu proyek konstruksi yang pada saat tahap pelaksanaannya melebihi anggaran biaya proyek yang telah ditetapkan di tahap awal, sehingga menimbulkan kerugian bagi pihak kontraktor (Santosa, 2009). Penambahan biaya sendiri dapat dibagi menjadi tiga tahap yaitu sebagai berikut.

a. Penambahan biaya (Cost Overrun) pada tahap awal proyek kontruksi

Penambahan biaya pada tahap awal proyek konstruksi terjadi karena beberapa hal yaitu proses kontrol kualitas material yang kurang baik, sehingga menyebabkan perlunya dilakukan pekerjaan ulang karena material tidak sesuai spesifikasi. Hal ini mengakibatkan adanya penambahan biaya baik yang digunakan untuk tenaga kerja maupun biaya pembelian kembali material yang akan digunakan. Estimasi biaya juga dapat menyebabkan penambahan biaya pada tahap awal konstruksi, hal ini dikarenakan ketidaktepatan pada saat melakukan estimasi tentang peralatan, jumlah pekerja dan kondisi lapangan menyebabkan berbagai masalah dalam tahap pelaksanaan proyek sehingga muncul biaya tak terduga yang akan memuat proyek mengalami penambahan biaya (cost overrun).

b. Penambahan biaya (Cost Overrun) pada saat proses proyek konstruksi

Penambahan biaya pada saatproses proyek konstruksi bisa terjadi karena berbagai hal antara lain adalah produktivitas pekerja yang buruk. Hal ini disebabkan oleh ketidakcakapan manajer proyek dalam mengatrur pekerjaan dan tenaga kerja, serta kualitas yang buruk dari tenaga kerja itu sendiri.

c. Penambahan biaya (Cost Overrun) pasca proyek konstruksi.

Faktor penyebab terjadinya penambahan biaya pasca proyek konstruksi adalah sebagai berikut.

1) Terjadi klaim karena hasil produk tidak sesuai mutu yang disepakati

2) Adanya keluhan dari owner karena adanya cacat pada masa pemeliharaan.

\section{METODOLOGI}

Penelitian ini dilakukan dengan melaksanakan penyebaran kuesioner pada kontraktor-kontraktor yang pernah menangani proyek jalan APBD Kabupaten Sragen pada tahun 2017 dan 2018, baik yang tinggal di Sragen maupun luar kota Sragen. Berdasarkan data yang diperoleh dari DPUPR Kabupaten Sragen, terdapat 132 proyek jalan APBD di Kabupaten Sragen pada tahun 2017 dan 2018. Penyebaran kuesioner dilaksanakan mulai tanggal 1 April 2019 sampai dengan 25 Mei 2019. 
Variabel independen merupakan variabel yang menyebabkan timbulnya variabel dependen. Variabel independen dalam penelitian ini adalah faktor-faktor yang menjadi penyebab penambahan biaya yang terjadi di Kabupaten Sragen tahun 2017 dan 2018, sedangkan variabel dependennya adalah penambahan biaya itu sendiri.

Teknik pengumpulan data adalah cara penulis untuk mendapatkan data yang memenuhi standar data yang telah ditetapkan. Penelitian ini menggunakan teknik pengumpulan data melalui wawancara dan penyebaran kuesioner.

a. Wawancara yaitu komunikasi dua arah yang dilakukan penulis untuk memperoleh data yang diinginkan. Dalam penelitian ini wawancara dilakukan peneliti saat akan melakukan penyusunan kuesioner, wawancara dilakukan peneliti dengan kontraktor yang pernah menangani proyek khususnya di Kabupaten Sragen. Dari hasil wawancara ini, peneliti memperoleh data primer yaitu berupa informasi tentang faktor penyebab penambahan biaya proyek di Kabupaten Sragen yang selanjutnya digunakan dalam penyusunan kuesioner.

b. Kuesioner adalah kumpulan dari beberapa pertanyaan ataupun pernyataan yang di berikan kepada responden agar memperoleh jawaban sebagai data yang akan digunakan untuk penelitian. (Sugiyono, 2008:199). Setelah kuesoner tersusun maka langkah selanjutnya adalah melakukan penyebaran kuesioner kepada kontraktor-kontraktor yang menangani proyek sesuai dengan data sekunder yang diperoleh dari Dinas Pekerjaan Umum dan Penataan Ruang
(DPUPR). Kuesioner yang akan disebar dibuat menggunakan skala likert. Jawaban dari setiap item instrumennya menggunakan skala likert yang akan diberi skor untuk keperluan analisis kuantitatifnya. Jawaban tersebut adalah sebagai berikut.

1) Sangat Tidak Setuju (STS) $=1$

2) Tidak Setuju (TS) $=2$

3) Ragu-Ragu (RR) $=3$

4) Setuju (S) $=4$

5) Sangat Setuju (SS) $=5$

Berikut adalah kuesioner yang digunakan dalam penelitian ini.

\begin{tabular}{|c|c|}
\hline Variabel & Item Pertanyaan \\
\hline \multirow{7}{*}{$\begin{array}{l}\text { Estimasi Biaya } \\
\qquad(\mathrm{X} 1)\end{array}$} & $\begin{array}{l}\text { Data dan informasi proyek } \\
\text { yang tidak lengkap }\end{array}$ \\
\hline & $\begin{array}{l}\text { Tidak memperhitungkan } \\
\text { pengaruh inflasi dan ekslasi }\end{array}$ \\
\hline & $\begin{array}{l}\text { Tidak memperhitungkan } \\
\text { biaya tak terduga }\end{array}$ \\
\hline & $\begin{array}{l}\text { Kurangnya K3 di lokasi } \\
\text { proyek }\end{array}$ \\
\hline & $\begin{array}{l}\text { Ketidaktepatan estimasi } \\
\text { biaya }\end{array}$ \\
\hline & $\begin{array}{l}\text { Biaya kompensasi } \\
\text { persengketaan sekitar } \\
\text { proyek/lingkungan proyek }\end{array}$ \\
\hline & $\begin{array}{l}\text { Kesalahan dalam perhitungan } \\
\text { desain dan engineering }\end{array}$ \\
\hline \multirow{7}{*}{$\begin{array}{l}\text { Pelaksanaan dan } \\
\text { Hubungan Kerja } \\
\text { (X2) }\end{array}$} & $\begin{array}{l}\text { Dampak adanya addendum } \\
\text { dan } C C O\end{array}$ \\
\hline & $\begin{array}{l}\text { Adanya kebijakan publik } \\
\text { yang baru dari pemerintah }\end{array}$ \\
\hline & $\begin{array}{l}\text { Penunjukkan subkontraktor } \\
\text { dan supplier yang tidak tepat }\end{array}$ \\
\hline & $\begin{array}{l}\text { Keterlambatan dalam } \\
\text { pengambilan keputusan }\end{array}$ \\
\hline & $\begin{array}{l}\text { Tidak memperhatikan resiko } \\
\text { lokasi dan konstruksi }\end{array}$ \\
\hline & $\begin{array}{l}\text { Kurang baik dalam } \\
\text { pembuatan jadwal dan } \\
\text { sumber daya }\end{array}$ \\
\hline & $\begin{array}{l}\text { Kurang tepat dalam } \\
\text { penempatan personil proyek } \\
\text { pada struktur organisasi }\end{array}$ \\
\hline \multirow{3}{*}{$\begin{array}{l}\text { Aspek Dokumen } \\
\text { (X3) }\end{array}$} & $\begin{array}{l}\text { Terdapat perbedaan kondisi } \\
\text { lapangan yang tertulis dalam } \\
\text { kontrak }\end{array}$ \\
\hline & $\begin{array}{l}\text { Jenis kontrak yang } \\
\text { digunakan }\end{array}$ \\
\hline & $\begin{array}{l}\text { Persetujuan masyarakat akan } \\
\text { didirikan suatu proyek }\end{array}$ \\
\hline Material (X4) & $\begin{array}{c}\text { Adanya kenaikan harga } \\
\text { material }\end{array}$ \\
\hline
\end{tabular}




\begin{tabular}{|c|l|}
\hline Variabel & \multicolumn{1}{|c|}{ Item Pertanyaan } \\
\hline \multirow{5}{*}{ Tenaga Kerja (X5) } & $\begin{array}{l}\text { Pemakaian bahan material } \\
\text { yang diimpor }\end{array}$ \\
\cline { 2 - 3 } & Pencurian bahan/material \\
\cline { 2 - 3 } & Kerusakan bahan/material \\
\cline { 2 - 3 } & $\begin{array}{l}\text { Keterlambatan penyediaan } \\
\text { material }\end{array}$ \\
\cline { 2 - 3 } Yang buruk
\end{tabular}

Penelitian ini menggunakan dua teknik analisis data yaitu analisis statistik deskriptif yang dilakukan untuk menggambarkan variabel penelitian dan analisis statistik inferensial yang dilakukan untuk memprediksi pengaruh variabel independen terhadap variabel dependen, berikut adalah analisis statistik inferensial yang dilakukan dalam penelitian ini.

a. Uji instrumen penelitian. Pengujian ini dilakukan untuk mengetahui apakah kuesioner yang dipakai sebagai alat pengukur dalam penelitian dapat digunakan atau tidak.

1) Uji validitas

Menurut Jogiyanto (2005), validitas adalah seberapa nyata suatu instrumen dapat mengukur apa yang akan diukur. Pengujiam validitas dilakukan dengan mengkorelasikan tiap butir dan skor total (corrected item total correlation) dengan menggunakan alat bantu program SPSS Ver 25.0. Uji validitas dilakukan dengan membandingkan nilai $r_{\text {hitung }}$ dengan $r_{\text {tabel }}$ menggunakan rumus koefisien korelasi product moment, dengan rumus sebagai berikut.

$\mathrm{r}_{\mathrm{xy}}=\frac{N \sum X Y\left(\sum X\right)\left(\sum Y\right)}{\sqrt{\left\{N \sum X^{2}-\left(\sum X\right)^{2}\right\}\left\{N \sum Y^{2}-\left(\sum Y\right)^{2}\right\}}}$

di mana:

$\mathrm{N}=$ jumlah responden

$\mathrm{X}=$ skor variabel (jawaban responden)

$\mathrm{Y}=$ skor total variabel responden $\mathrm{N}$

Berikut adalah kriteria pengambilan keputusan pada pengujian validitas.

a. Jika nilai $\mathbf{r}_{\text {hitung }}>$ nilai $r_{\text {tabel }}$ dan nilai sig. $<0,05$ maka dapat dinyatakan valid

b. Jika nilai $r_{\text {hitung }}<$ nilai $r_{\text {tabel }}$ dan nilai sig. > 0,05 maka dapat dinyatakan tidak valid.

2) Uji reliabilitas

Reliabilitas adalah keakuratan atau ketepatan suatu pengukuran (Jogiyanto, 2005). Suatu instrumen penelitian dikatakan dapat reliabel atau dapat dipercaya jika memiliki hasil yang akurat atau konsisten. Siregar (2010:175) menyatakan bahwa suatu data dikatakan reliabel jika nilai cronbach alpha $>0,6$. Berikut adalah rumus reliabilitas dengan metode cronbach alpha:

$\mathrm{r}_{11}=\left[\frac{k}{n-1}\right]\left[1-\frac{\sum \sigma b^{2}}{\sigma t^{2}}\right]$

di mana:

$\mathrm{n} \quad=$ jumlah sampel

$\mathrm{X}=$ nilai skor yang dipilih

$\sigma_{\mathrm{t}}^{2}=$ varians total

$\sum \sigma_{\mathrm{b}}{ }^{2}=$ jumlah varian butir

$\mathrm{k} \quad=$ jumlah butir pertanyaan 
$\mathrm{r}_{11}=$ koefisien reliabilitas instrumen

b. Uji asumsi klasik, uji ini dilakukan sebagai prasyarat untuk melakukan analisis regresi berganda dalam penelitian ini.

\section{1) Uji normalitas}

Uji normalitas adalah uji yang digunakan untuk mengetahui apakah nilai residual yang dihasilkan dari model regresi dalam penelitian ini terdistribusi secara normal atau tidak. Uji normalitas yang dilakukan dengan mendasarkan pada uji One Sample Kolmogorov-Smirnov (KS), kriteria yang digunakan adalah jika nilai Asym. Sig. (2-tailed) $>0,05$ maka data pada suatu penelitian dapat dikatakan terdistribusi normal (Sugiyono dan Susanto, 2015: 323). Sedangkan uji normalitas yang dilakukan dengan metode grafik dapat dideteksi dengan melihat hasil penyebaran dari plotting variabel $\mathrm{X}$ dan $\mathrm{Y}$, jika hasil plotting menyebar disekitar garis diagonal maka data residual dapat dikatakan terdistribusi secara normal. (Supriyadi, 2014: 84). Model regresi yang baik adalah regresi yang memiliki nilai residual terdistribusi secara normal.

2) Uji multikolinieritas

Uji multikolinieritas dilakukan untuk mengetahui ada atau tidaknya korelasi antar variabel bebas pada suatu model regresi linier berganda. (Sunjoyo, dkk. 2013: 65). Suatu model regresi dapat dikatakan terbebas dari multikolinieritas jika nilai VIF tidak lebih dari 10 (VIF < 10) dan nilai Tolerance tidak kurang dari 0,1 (Tolerance $>0,1)$. Menurut Priyastama (2017), model regresi yang baik seharusnya tidak terjadi korelasi antar variabel bebasnya.
3) Uji heteroskedastisitas

Uji heteroskedastisitas dilakukan untuk melihat adanya perbedaan varians dari residual pada suatu model regresi. Model regresi yang memenuhi persyaratan adalah model regresi yang memiliki kesamaan varians atau biasa disebut homoskedastisitas. (Sunjoyo, dkk. 2013: 69). Pengambilan keputusan dalam uji heteroskedastisitas adalah sebagai berikut.

a) Jika titik-titik membentuk pola secara teratur, maka data tersebut terjadi heteroskedastisitas.

b) Jika titik-titik menyebar diatas dan dibawah angka 0 pada sumbu $\mathrm{Y}$ (menyebar), maka data tersebut tidak terjadi heteroskedastisitas.

(Priyastama, 2017: 128).

c. Analisis regresi berganda. Analisis ini digunakan untuk memprediksi variabel dependen dengan menggunakan variabel independen yang jumlahnya lebih dari satu. (Priyastama, 2017: 154). Rumus regresi linier berganda adalah sebagai berikut.

$\mathrm{Y}=\mathrm{a}+\mathrm{b}_{1} X_{1}+\mathrm{b}_{2} X_{2}+\mathrm{b}_{3} X_{3}+\ldots+\mathrm{b}_{\mathrm{n}} X_{n} \ldots .$. (3) dimana:

$\mathrm{Y}=$ variabel dependen

$X_{1} \quad=$ variabel independen pertama

$X_{2} \quad=$ variabel independen kedua

$X_{3} \quad=$ variabel independen ketiga

$X_{n} \quad=$ variabel independen ke-n

a $\quad=$ konstanta

$\mathrm{b}_{1}, \mathrm{~b}_{2}, \mathrm{~b}_{3}$, dst $=$ koefisien

pengukuran.

d. Pengujian hipotesis

1) Uji koefisien regresi parsial (Uji t) Uji ini digunakan untuk mengetahui secara parsial pengaruh signifikan variabel independen terhadap variabel dependen. 
2) Uji koefisien regresi simultan (Uji F)

Uji ini digunakan untuk mengetahui pengaruh signifikan variabel independen terhadap variabel dependen secara simultan/bersamasama.

3) Uji koefisien determinasi

Uji ini digunakan untuk mengetahui besarnya pengaruh variabel independen terhadap variabel dependen secara simultan/bersamasama.

\section{HASIL DAN PEMBAHASAN}

a. Hasil uji instrumen penelitian

1) Uji validitas

Dari hasil analisis validitas dapat diketahui bahwa variabel yang digunakan dalam penelitian ini dapat dikatakan valid, kerena memiliki nilai $r_{\text {hitung }}>$ nilai $r_{\text {tabel }}$ dan nilai sig. $<0,05$.

2) Hasil uji reliabilitas

Berdasarkan analisis reliabilitas yang telah dilakukan dapat diketahui bahwa terdapat dua variabel yang tidak reliabel yaitu variabel aspek dokumen (X3) dan keuangan proyek (X7) karena memiliki nilai cronbach aplha $<0,6$.

b. Uji asumsi klasik

1) Uji normalitas

Dari hasil analisis uji normalitas yang dilakukan dengan bantuan program aplikasi SPSS Ver 25.0, diperoleh hasil analisis uji normalitas sebagai berikut.

Tabel 1. Hasil uji one sample kolmogorov-smirnov

\begin{tabular}{|c|c|}
\hline \multicolumn{2}{|c|}{ One-Sample Kolmogorov-Smirnov Test } \\
\hline & $\begin{array}{c}\text { Unstandar } \\
\text { dized } \\
\text { Residual } \\
\end{array}$ \\
\hline $\mathrm{N}$ & 98 \\
\hline & .0000000 \\
\hline
\end{tabular}

\begin{tabular}{llr}
\hline \multicolumn{2}{c}{ One-Sample Kolmogorov-Smirnov Test } \\
\hline Normal & Std. & .08724213 \\
Parameters ${ }^{\mathrm{a}, \mathrm{b}}$ & Deviation & \\
\hline Most Extreme & Absolute & .086 \\
\cline { 2 - 3 } Differences & Positive & .086 \\
\cline { 2 - 3 } & Negative & -.055 \\
\hline Test Statistic & .086 \\
\hline Asymp. Sig. (2-tailed) & .073 \\
\hline a. Test distribution is Normal. & \\
\hline
\end{tabular}

Sumber: Analisis Data SPSS, 2019.

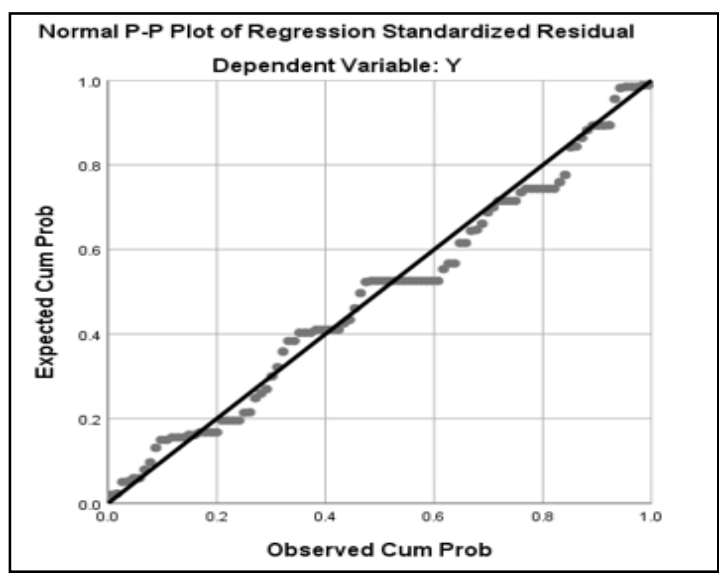

Gambar 1. P-P plot of regression

Dari pengujian one sample kolmogorov-smirnov dapat diketahui bahwa nilai Asymp. Sig. (2-tailed) adalah sebesar 0,073 ( > 0,05 ) dan hasil plotting $P-P$ plot of regression menyebar disekitar garis diagonal, sehingga dapat dikatakan bahwa residual dari model regresi pada penelitian ini memiliki distribusi normal.

2) Uji multikolinieritas

Uji multikolinieritas dalam penelitian ini dilakukan dengan pengolahan data menggunakan program SPSS Ver 25.0 dan dapat dilihat pada tabel 2 .

Tabel 2. Hasil uji multikolinieritas

\begin{tabular}{lccl}
\hline Variabel & $\begin{array}{c}\text { Nilai } \\
\text { VIF }\end{array}$ & Tolerance & Keterangan \\
\hline $\begin{array}{l}\text { Estimasi } \\
\text { Biaya (X1) }\end{array}$ & 4,260 & 0,235 & $\begin{array}{l}\text { Non } \\
\text { Multikolinieritas }\end{array}$ \\
\hline $\begin{array}{l}\text { Pelaksanaan } \\
\text { dan }\end{array}$ & 4,586 & 0,218 & $\begin{array}{l}\text { Non } \\
\text { Multikolinieritas }\end{array}$ \\
$\begin{array}{l}\text { Hubungan } \\
\text { Kerja (X2) }\end{array}$ & & & \\
\hline Material (X4) & 3,277 & 0,305 & $\begin{array}{l}\text { Non } \\
\text { Multikolinieritas }\end{array}$ \\
\hline
\end{tabular}




\begin{tabular}{lccl}
\hline Variabel & $\begin{array}{c}\text { Nilai } \\
\text { VIF }\end{array}$ & Tolerance & Keterangan \\
\hline $\begin{array}{l}\text { Tenaga Kerja } \\
\text { (X5) }\end{array}$ & 3,325 & 0,301 & $\begin{array}{l}\text { Non } \\
\text { Multikolinieritas }\end{array}$ \\
\hline $\begin{array}{l}\text { Peralatan } \\
\text { (X6) }\end{array}$ & 3,173 & 0,315 & $\begin{array}{l}\text { Non } \\
\text { Multikolinieritas }\end{array}$ \\
\hline $\begin{array}{l}\text { Waktu } \\
\text { Pelaksanaan } \\
\text { (X8) }\end{array}$ & 3,875 & 0,258 & $\begin{array}{l}\text { Non } \\
\text { Multikolinieritas }\end{array}$ \\
\hline $\begin{array}{l}\text { Pengaturan } \\
\text { Lapangan } \\
\text { (X9) }\end{array}$ & 2,044 & 0,489 & $\begin{array}{l}\text { Non } \\
\text { Multikolinieritas }\end{array}$ \\
\hline
\end{tabular}

Sumber: Analisis Data SPSS, 2019.

Dari tabel 2 diketahui bahwa tidak terjadi multikolinieritas antar variabel independen dalam penelitian ini, sehingga dapat dinyatakan memenuhi uji syarat analisis regresi berganda.

3) Uji heteroskedastisitas

Gambar 2 adalah hasil uji heteroskedastisitas yang dilakukan dengan bantuan program SPSS Ver 25.0.

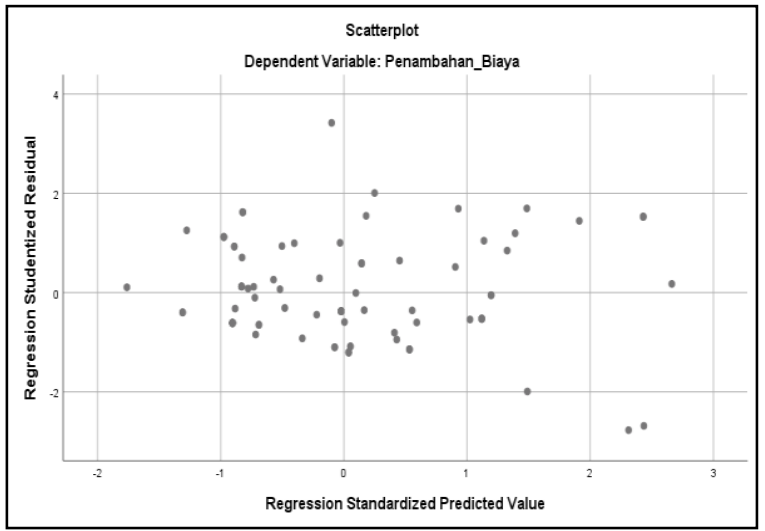

Gambar 2. Diagram pencar variabel $\mathrm{X}$ terhadap Y

c. Analisis regresi berganda

Data yang memenuhi uji asumsi klasik, kemudian digunakan untuk melakukan analisis ini. Berikut adalah hasil analisis regresi berganda dengan menggunakan program SPSS Ver 25.0.

Tabel 3. Hasil perhitungan analisis regresi berganda Coefficients $^{\mathrm{a}}$

\begin{tabular}{cccccc}
\hline Model & B & $\begin{array}{c}\text { Std. } \\
\text { Error }\end{array}$ & Beta & t & Sig. \\
\hline (Constant) & .440 & .120 & & 3.658 & .000 \\
\hline
\end{tabular}

\begin{tabular}{|c|c|c|c|c|c|}
\hline \multicolumn{6}{|c|}{ Coefficients $^{\mathrm{a}}$} \\
\hline $\begin{array}{l}\text { Estimasi } \\
\text { Biaya }\end{array}$ & .103 & .018 & 1.041 & -5.835 & 000 \\
\hline $\begin{array}{l}\text { Pelaksanaan } \\
\text { dan } \\
\text { Hubungan } \\
\text { Kerja }\end{array}$ & .078 & .010 & 1.547 & 7.640 & 000 \\
\hline Material & .066 & .010 & -.658 & -6.586 & 000 \\
\hline Tenaga Kerja & .000 & .016 & -.002 & -.016 & 987 \\
\hline Peralatan & .061 & .010 & .624 & 6.245 & 000 \\
\hline $\begin{array}{l}\text { Waktu } \\
\text { Pelaksanaan }\end{array}$ & .004 & .016 & -.030 & -.268 & 789 \\
\hline $\begin{array}{l}\text { Pengaturan } \\
\text { Lapangan }\end{array}$ & .025 & .016 & -.111 & -1.525 & 131 \\
\hline
\end{tabular}

Sumber: Analisis Data SPSS, 2019.

Tabel 3 menunjukkan bahwa persamaan regresi yang terbentuk dalam penelitian ini yaitu sebagai berikut.

$$
\begin{aligned}
\mathrm{Y} & =0,440-0,103 \cdot \mathrm{X} 1+0,780 \cdot \mathrm{X} 2-0,066 \cdot \mathrm{X} 4 \\
& +0,000 \cdot \mathrm{X} 5+0,061 \cdot \mathrm{X} 6-0,004 \cdot \mathrm{X} 8- \\
& \text { 0,025.X } 9+\varepsilon
\end{aligned}
$$

d. Pengujian hipotesis

1) Uji koefisien regresi parsial (Uji t)

Uji t pada penelitian ini menggunakan program SPSS Ver 25.0. Dengan tingkat kepercayaan $95 \%$, diperoleh $t_{\text {tabel }}$ sebesar 1,990. Hasil uji t tersebut dapat dilihat pada tabel 4 .

Tabel 4. Hasil uji t

\begin{tabular}{lccl}
\hline \multicolumn{1}{c}{ Variabel } & thitung & Sig. & Keterangan \\
\hline $\begin{array}{l}\text { Estimasi } \\
\text { Biaya }\end{array}$ & $-5,835$ & 0,000 & $\begin{array}{l}\text { Tidak } \\
\text { signifikan }\end{array}$ \\
\hline $\begin{array}{l}\text { Pelaksanaan } \\
\text { danHubungan } \\
\text { Kerja }\end{array}$ & 7,640 & 0,000 & Signifikan \\
\hline Material & $-6,586$ & 0,000 & $\begin{array}{l}\text { Tidak } \\
\text { signifikan }\end{array}$ \\
\hline Tenaga Kerja & $-0,016$ & 0,987 & $\begin{array}{l}\text { Tidak } \\
\text { signifikan }\end{array}$ \\
\hline Peralatan & 6,245 & 0,000 & Signifikan \\
\hline $\begin{array}{l}\text { Waktu } \\
\text { Pelaksanaan }\end{array}$ & $-0,268$ & 0,789 & $\begin{array}{l}\text { Tidak } \\
\text { signifikan }\end{array}$ \\
\hline $\begin{array}{l}\text { Pengaturan } \\
\text { Lapangan }\end{array}$ & $-1,525$ & 0,131 & $\begin{array}{l}\text { Tidak } \\
\text { signifikan }\end{array}$ \\
\hline Sumber: Analisis Data SPSS & 2019.
\end{tabular}

Sumber: Analisis Data SPSS, 2019.

Dari tabel 4 dapat diketahui bahwa variabel pelaksanaan \& hubungan kerja dan peralatan berpengaruh signifikan terhadap variabel dependen secara parsial. 2) Uji koefisien regresi simultan (Uji F) 
Uji $F$ dilakukan dengan cara membandingkan nilai $F_{\text {hitung }}$ dan $F_{\text {tabel }}$ pada tabel ANOVA hasil analisis regresi linier berganda. Dengan menggunakan program SPSS Ver 25.0 diperoleh tabel ANOVA hasil regresi linier berganda pada tabel 5 .

\begin{tabular}{ccccl}
\multicolumn{5}{c}{ Tabel 5. Hasil uji F } \\
\hline Model & F $_{\text {hitung }}$ & Sig. & F tabel & Kesimpulan \\
& & & & \\
\hline 1. & 34,987 & 0,000 & 2,021 & Signifikan
\end{tabular}

Sumber: Analisis Data SPSS, 2019.

Dari tabel 5 dapat disimpulkan bahwa variabel independen berpengaruh signifikan terhadap variabel dependen secara simultan.

3) Uji koefisien determinasi

Hasil uji koefisien determinasi dalam penelitian ini dapat dilihat pada tabel 6 .

Tabel 6. Hasil uji determinasi

\begin{tabular}{|c|c|c|c|c|}
\hline \multicolumn{5}{|c|}{ Model Summary } \\
\hline Model & $\mathrm{R}$ & $\begin{array}{c}\mathrm{R} \\
\text { Square }\end{array}$ & $\begin{array}{l}\text { Adjusted } \\
\text { R Square }\end{array}$ & $\begin{array}{l}\text { Std. Error of } \\
\text { the Estimate }\end{array}$ \\
\hline 1 & $.855^{\mathrm{a}}$ & .731 & .710 & .214 \\
\hline \multicolumn{5}{|c|}{$\begin{array}{l}\text { a. Predictors: (Constant), Pengaturan Lapangan, } \\
\text { Estimasi Biaya, Material, Tenaga Kerja, Peralatan, } \\
\text { Waktu Pelaksanaan, Pelaksanaan dan Hubungan } \\
\text { Kerja }\end{array}$} \\
\hline
\end{tabular}

Sumber: Analisis Data SPSS, 2019.

Berdasarkan uji determinasi yang telah dilakukan dapat diketahui bahwa variabel independen berpengaruh secara bersamasama sebesar $73.1 \%$ terhadap variabel dependen dan sisanya dipengaruhi oleh variabel-variabel lain diluar model regresi yang dimasukkan dalam penelitian ini.

Faktor dominan dalam penelitian ini dapat diketahui dengan melihat koefisien $\beta$ terbesar pada analisis regresi berganda dalam penelitian ini. Berdasarkan nilai koesifien $\beta$ pada penelitian ini, dapat diketahui bahwa faktor yang memiliki pengaruh paling dominan terhadap penambahan biaya pada proyek jalan APBD di Kabupaten Sragen tahun 2017 dan 2018 adalah variabel pelaksanaan dan hubungan kerja.

\section{SIMPULAN}

Kesimpulan dari penelitian ini adalah sebagai berikut.

1. Faktor yang menjadi penyebab terjadinya penambahan biaya pada proyek jalan APBD Kabupaten Sragen tahun 2017 dan 2018 adalah pelaksanaan \& hubungan kerja dan peralatan.

2. Faktor paling dominan yang menyebabkan penambahan biaya proyek jalan APBD Kabupaten Sragen tahun 2017 dan 2018 adalah pelaksanaan dan hubungan kerja.

\section{SARAN}

Berdasarkan penelitian yang telah dilakukan ada beberapa hal yang ingin disampaikan sebagai saran adalah sebagai berikut.

1. Hasil penelitian hendaknya digunakan sebagai alat bantu kontraktorkontraktor yang akan melaksanakan proyek jalan di Kabupaten Sragen untuk mengantisipasi terjadinya penambahan biaya (cost overrun).

2. Sebelum memulai pelaksanaan proyek sebaiknya kontraktor lebih memperhatikan faktor-faktor yang mungkin bisa menyebabkan penambahan biaya (cost overrun).

3. Sebaiknya pengisian kuesioner dilakukan oleh staff engineer atau direktur yang mengetahui dengan pasti hal-hal yang berkaitan dengan pelaksanaan dan pembiayaan proyek sehingga hasil penelitian bisa lebih valid. 
4. Dalam pengambilan data, sebaiknya pengisian kuesioner didampingi oleh peneliti agar data yang diterima lebih valid dan tidak menghambat waktu penelitian.

\section{DAFTAR PUSTAKA}

Dimyati dan Nurjaman (2014). Manajemen Proyek. Bandung: Pustaka Setia.

Jogiyanto, H.M. (2005). Analisa dan Desain Sistem Informasi: Pendekatan Terstruktur Teori dan Praktik Aplikasi Bisnis. Yogyakarta : Andi.

Manullang, Rio. (2015). Buku Pintar Menghitung Biaya Bangunan. Yogyakarta: Andi.

Natan Ishak. (1986). Manajemen Proyek Konstruksi 2. Surabaya: Kartika

Yudha Priyastama, Romie. (2017). Buku Sakti Kuasai SPSS. Yogyakarta: Start Up.

Santosa, B. (2009). Manajemen Proyek Konsep dan Implementasi. Yogyakarta: Graha Ilmu.

Siregar, Syofian. (2010). Statistika Deskriptif untuk Penelitian. Jakarta: Rajagrafindo Persada.

Sugiyono. (2008). Penelitian Pendidikan Pendekatan Kuantitatif, kualitatif, dan R\&D. Bandung: Alfabeta.

Sugiyono dan Susanto. (2015). Cara Mudah Belajar SPSS dan Lisrel. Bandung: Alfabeta.

Sunjoyo, dkk. (2013). Aplikasi SPSS untuk SMART Riset. Bandung: Alfabeta.

Supriyadi, Edy. (2014). SPSS + AMOS. Jakarta: In Media. 